\title{
Cinsiyetin Dini Başa Çıkma Üzerindeki Etkisi: Meta - Analiz
}

\section{The Effect of Gender on Religious Coping: Meta-Analysis}

\section{Soner ERCAN}

Uludağ Üniversitesi, Sosyal Bilimler Enstitüsü

PhD. Student, Uludağ University, Institut of Social Sciences, Bursa, Turkey.

berson8282@gmail.com

(iD) $0000-0002-0383-513 \mathrm{X}$

\section{Doç. Dr. M. Naci KULA}

Uludağ Üniversitesi, Eğitim Fakültesi, Hayat Boyu Öğrenme ve Yetişkin Eğitimi Bölümü

Dr., Uludağ University, Faculty of Education, Department of Lifelong Learning and Adult Education, Bursa, Turkey.

nkula@yahoo.com

(iD) $0000-0003-1703-9620$

\begin{tabular}{lcc}
\multicolumn{2}{c}{ Makale Bilgisi / Article Information } & \\
& Makale Türü / Article Type & Araştırma Makalesi / Research Article \\
Geliş Tarihi / Received & Kabul Tarihi / Accepted & Yayın Tarihi / Published \\
03 Haziran / June 2021 & 05 Eylül / September 2021 & 23 Eylül / September 2021
\end{tabular}

\section{Atıf Bilgisi / Cite as:}

Ercan, Soner - Kula, Mustafa Naci. “Cinsiyetin Dini Başa Çıkma Üzerindeki Etkisi: Meta - Analiz”, Eskişehir Osmangazi Üniversitesi İlahiyat Fakültesi Dergisi 8/2 (Eylül 2021), 210-228.

http://doi.org/1051702/esoguifd.949743

İntihal / Plagiarism: Bu makale, en az iki hakem tarafından incelenmiş ve intihal içermediği teyit edilmiştir. / This article has been reviewed by least two referees and scanned via a plagiarism software.

Copyright @ Published by Eskişehir Osmangazi Üniversitesi, İlahiyat Fakültesi /Eskişehir Osmangazi University, Faculty of Theology Bütün hakları saklıdır. / All right reserved. https://dergipark.org.tr/tr/pub/esoguifd

CC BY-NC 4.0 This paper is licensed under a Creative Commons Attribution-NonCommercial License

Etik Beyanı / Ethical Statement: Bu çalışmanın hazırlanma sürecinde bilimsel ve etik ilkelere uyulduğu, yararlanılan tüm çalışmaların kaynakçada belirtildiği ve bu araştırmanın desteklenmesi için herhangi bir dış fon almadıkları yazar tarafından beyan olunur / It is declared by the author that scientific and ethical principles have been followed while carrying out and writing this study; that all the sources used have been properly cited; that no external funding was received in support of the research. 


\section{Cinsiyetin Dini Başa Çıkma Üzerindeki Etkisi: Meta - Analiz}

Öz • Dini başa çıkmanın üzerinde cinsiyetin etkisini anlamak için meta - analiz araştırması yapılmıştır. Din psikolojisi alanında dini başa çıkma ile ilgili yapılan ilk meta-analiz olması araştırmanın önemini daha da arttırmaktadır. Meta - analiz araştırması için dahil edilme kriterleri belirlenmiş, belirlenen kriterlere göre dahil edilecek çalışmaların seçimi akış şeması doğrultusunda yapılmıştır. Meta - analize dâhil edilme kriterlerine uygun olan 10 adet tez kullanılmıştır. Verilerin anlamlı hale getirilmesi için CMA (versiyon 3) programı kullanılmıştır. Analiz sürecinde etki büyüklükleri ve heterojenlik testleri yapılmış, etki büyüklüğünü tanımlamak için Hedges's $g$ değerleri hesaplanmıştır. Etki büyüklüklerine ilişkin orman ve yayım yanlılı̆̆ının tespiti için huni grafikleri yapılmıştır. Olumlu dini başa çıkma için erkekler lehine önemsiz düzeyde ( $g=-0,009)$, olumsuz dini başa çıkma için kadınlar lehine önemsiz düzeyde $(g=0,099)$ etki büyüklüğü tespit edilmiştir. Cinsiyetin dini başa çıkma düzeyine etki etmediği tespit edilmiştir.

Anahtar Kelimeler: Felsefe ve Din Bilimleri, Din Psikolojisi, Cinsiyet, Dini Başa Çıkma, Meta-Analiz.

\section{The Effect of Gender on Religious Coping: Meta-Analysis}

Abstract Meta-analysis research was conducted to understand the effect of gender on religious coping. The fact that it is the first meta-analysis on religious coping in the psychology of religion further increases the importance of the research. Inclusion criteria were determined for the meta-analysis research, and the selection of the studies to be included according to the determined criteria was made in line with the flow chart. 10 dissertations that met the inclusion criteria of the meta-analysis were used. CMA (version 3) program was used to make the data more meaningful. During the analysis process, effect sizes and heterogeneity tests were performed, and Hedges's $g$ values were calculated to define the effect size. Funnel plots were made to determine the forest and publication bias regarding the effect sizes. The effect size was insignificant in favor of men ( $g=-0.009)$ for positive religious coping, and insignificant in favor of women $(\mathrm{g}=0.099)$ for negative religious coping. It was determined that gender did not affect the level of religious coping.

Keywords: Study of Religion and Philosophy, Psychology of Religion, Gender, Religious Coping, Meta-Analysis.

\section{Giriş}

Din, kaygı azaltma, anlam arayışı gibi birden çok amaca hizmet edebilmektedir. Ayrıca din, dayanışma ve bağlılık gibi sosyal amaçlarla da bağlantılıdır. Dini başa çıkma, çok yönlü ve karmaşık bir yapıya sahip olan başa çıkmanın başka bir yoludur. Dini başa çıkma bireyin yaşantısında somutlaşabilme özelliğine sahip bir kavramdır. ${ }^{1}$ Din, olumsuz yaşantıların görmezden gelinip reddedilmeyerek, yaşantıların tekrar değerlendirilmesini sağlamaktadır. Böylece bireylerin

\footnotetext{
${ }^{1}$ Kenneth I. Pargament - Hisham Abu Raiya, "A Dedace of Research on the Psychology of Religion and Coping: Things we assumed and lessons we learned”, Psyke \& Logos 28 (2007), 743-745.
} 
yaşadığı sıkıntılı zamanlar bireylerin gelişimi için de imkân sağlamış olmaktadır. ${ }^{2}$ İnsanoğlu, üstesinden gelmekte zorlandığı yaşam olayları karşısında ve sevdiği birinin kaybı gibi durumlarda güvenli bir yer olarak gördüğü dine sığınır. ${ }^{3}$ Din aynı zamanda amaçlar ve yöntemlerle de ilgilidir. İnsanların bireysel ve toplu olarak hayatlarında ne için çabalamaları gerektiğine dair nihai bir vizyon, herhangi bir dinin yüzeysel etkilerinin çok altında olmayan derinliklerinde bulunabilir. Ancak din, vizyon sunmaktan daha fazlasını da yapmaktadır. Bağlılarına bir dizi pratik yöntem ve onların nihai hedeflerine doğru yürüyebilmeleri için "harita" sağlamaktadır. ${ }^{4}$ Beklendiği üzere bağlamsal bir perspektiften bakıldığında, ruhsal ve dini başa çıkma stratejileri, insanın strese verdiği tepkinin hemen hemen her alanında tanımlanabilir ve dahası sürecin tek bir özelliği, dini/manevi başa çıkmanın tek, evrensel çekirdeği değildir. ${ }^{5}$ Pargament vd. (1998) dini başa çıkmayı, Tanrı ile güvenli bir ilişkinin, hayatta bulunmanın bir anlamı olduğuna dair bir inancın ve başkalarıyla manevi bir bağlılık duygusunun bir ifadesi olduğunu varsaydıkları olumlu dini başa çıkma ve Tanrı ile daha az güvenli bir ilişkinin, anlam arayışında dini bir mücadelenin bir ifadesi olduğunu varsaydıkları olumsuz dini başa çıkma şeklinde belirlemeye çalışmıştır. ${ }^{6}$ Dini benzersiz kılan şey, bu anlam arayışında kutsal olanın katılımıdır. Dini/manevi başa çıkmayı ayırt eden ise manevi kaynakların (kişisel veya sosyal), kutsal önemi hesaba katan değerlendirme süreçlerinin veya kutsal arayışı kabul eden başa çıkma sonuçlarının seçilmesidir. Diğer alanlarda olduğu gibi, herhangi bir özel strateji, kaynaklarda farklı talepler veya sorunlarla karşı karşıya kalan farklı insanlar için farklı şekilde işleyebilir. Örneğin, dua uygulamaları bir keder durumunda duygu odaklı başa çıkma işlevi görebilirken, başka bir durumda, kardiyak rehabilitasyon hastası için uyarılma azaltmanın problem odaklı başa çıkma yöntemi olarak hizmet edebilmektedir.? Dini başa çıma ve cinsiyet ile ilgili yapılan çalışmalarda cinsiyetin dini başa çıkma düzeyini değiştirmediği ${ }^{8}$ veya değiştirdiği ${ }^{9}$ gibi farklı

\footnotetext{
${ }^{2}$ Kenneth I. Pargament vd., “Başa Çıkmanın Dinî Boyutu: Teori, Araştırma ve Uygulamadaki Gelişmeler”, çev. Çiğdem Damla Balaban, Din ve Maneviyat Psikolojisi Yeni Yaklaşımlar ve Uygulama Alanları, çev. ed. İhsan Çapcıŏlu - Ali Ayten, der. Raymond F. Paloutzian - Crystal L. Park (Ankara: Phoenix, 2013), 381-382.

${ }^{3}$ Ali Ayten, Tanrı’ya Sığınmak Dinî Başa Çıkma Üzerine Psiko-Sosyal Bir Araştırma (İstanbul: İz Yayıncılık, 2012), 65.

${ }^{4}$ Kenneth I. Pargament, "Of Means and Ends: Religion and the Search for Significance", International Journal for the Psychology of Religion 2 (1992), 221-229'den akt. Kenneth I. Pargament - Crystal L. Park, "Merely a Defense? The Variety of Religious Means and Ends", Journal of Social Issues 51/2 (1995), 15.

${ }^{5}$ Derrick W. Klaassen vd., "Advance in the Study of Religious and Spiritual Coping”, Handbook of Multicultural Perspectives on Stress and Coping, ed. Paul T. P. Wong - Lilian C. J. Wong (USA: Springer, 2006), 112.

${ }^{6}$ Kenneth I. Pargament vd., "Patterns of Positive and Negative Religious Coping with Major Life Stressors", Journal for the Scientific Study of Religion 37/4 (1998), 712.

${ }^{7}$ Klaassen vd., "Advance in the Study of Religious and Spiritual Coping”, 108.

${ }^{8}$ Halil Ekşi, Başaçıkma, Dini Başaçıkma ve Ruh Sağlığı Arasındaki İlişki Üzerine Bir Araştırma: Eğitim, İlahiyat ve Mühendislik Fakültesi Öğrencilerinin Karşılaştırılması (Bursa: Uludağ Üniversitesi Sosyal Bilimler Enstitüsü, Doktora, 2001), 101.; Ayşe Şentepe, “Yaşlılık Döneminde Dini Başaçıkma”, İnsan ve Toplum Bilimleri Araştırmaları Dergisi 4/1 (2015), 194.

${ }^{9}$ Ali Ayten - Refik Yıldız, “Ali Ayten, Refik Yıldız-Dindarlık, Hayat Memnuniyeti İlişkisinde Dinî Başa Çıkmanın Rolü Nedir Emekliler Üzerine Bir Araştırma”, Dinbilimleri Akademik Araştırma Dergisi 16/1 (2016), 294-295.; Ayşe Murat -
} 
sonuçlar tespit edilmiştir. Alanda dini başa çıkma ile ilgili yoğun çalışmaların yapılmış olması, dini başa çıkmanın cinsiyet gibi temel bir değişken tarafından etkilenip etkilenmediğinin anlaşılmaya çalışılmasının gerekliliğine sebep olmaktadır. Dini başa çıkma düzeyinin değişmesi veya değişmemesi gibi farklılığın oluşmasının sebebi cinsiyet ile birlikte farklı değişkenlerin de rol oynaması olabilir. Araştırmaya dâhil edilen çalışmaların verileri ile daha geniş bir bilgi verme imkânı sunan meta-analiz sayesinde daha büyük bir örneklem grubunda cinsiyet ile dini başa çıkma arasındaki ilişkinin anlaşılması amaçlanmıştır. Ayrıca alanda dini başa çıkma ilgili meta - analiz araştırmasının yapılmamış olması, araştırmanın önemini ve literatüre sağladığı katkıyı ifade etmektedir.

\section{Yöntem}

\subsection{Meta - Analiz}

Küçük örneklemli tipik psikolojik araştırmalar görünüşte çelişkili sonuçları inceler ve istatistiksel anlamda daha karmaşık görünen çalışmalara dayanır. Meta-analiz, araştırma literatürünün altını çizen daha basit ilişki modellerini ortaya çıkarmak için bulguları bu tür çalışmalarla birleştirir ve böylece teori geliştirme için bir temel sağlar. Meta analiz, örnekleme hatası, ölçüm hatası ve çelişkili bulgular yanılsamasına neden olan diğer yapaylıkların bozucu etkilerini de düzeltebilir. ${ }^{10}$ Birçok sistematik inceleme ve meta-analiz, önceki çalışmaların sonuçlarına ilişkin etkileri özetlemektedir. Meta-analiz, birçok çalışmanın sonuçlarını özetleyen etkili bir yoldur. Böylece meta-analiz, daha önce tanımlanmamış ilişkileri ortaya çıkarabilir. Dikkatli bir şekilde yürütüldüğünde, sistematik inceleme ve meta analizler, araştırma bulgularının anlatı ve geleneklerinde bulunmayan bir şeffaflık sunmaktadır. ${ }^{11}$

\subsection{Meta-Analize Dâhil Edilme Kriterleri}

Araştırmaya dâhil edilen çalışmaların seçiminde YÖK Ulusal Tez Merkezinin internet sitesi temel alınmış, tarama yapılırken çalışmanın doğrudan "Dini Başa Çıkma" konusu ile ilgili olması taramanın temel noktasını oluşturmuştur.

Araştırmaya dâhil edilen çalışmaların seçiminde dikkate alınan dâhil edilme kriterleri aşağıda belirtilmiştir:

Muhammed Kızılgeçit, “Dini Başa Çıkma ve Psikopatoloji İlişkisi (Rize Örneği)”, Recep Tayyip Erdoğan Üniversitesi İlahiyat Fakültesi Dergisi 6/11 (30 Haziran 2017), 123-124; Zeynep Özcan, "Mülteci Öğrencilerin Kültürel Uyumları ile Dinî Başa Çıkmaları Arasındaki İlişki Üzerine Bir Araştırma”, Cumhuriyet İlahiyat Dergisi 23/1 (15 Haziran 2019), 138.

${ }^{10}$ John E. Hunter - Frank L. Schmidt, Methods of Meta-Analysis: Correcting Error and Bias in Research Findings (USA: Sage Publications, 2015), 17.

${ }^{11}$ Julia H. Littell vd., Systematic Reviews and Meta-Analysis (New York: Oxford University Press, 2008), 7-10.

$\overline{4 \mid} \quad$ Journal of Eskişehir Osmangazi University Faculty of Theology 
1- Çalışmanın 2019 veya 2020 yllında yapılmış ve çalışmanın YÖK Ulusal Tez Merkezinin internet sitesinde kayitlı olması ve yer alması.

2- Çalışmanın Üniversitelerin Sosyal Bilimler Enstitüsü Felsefe ve Din Bilimleri Ana Bilim Dalında yapılmış yüksek lisans veya doktora tezi olması.

3- Çalışmada kullanılan Dini Başa Çıkma ölçeğinin alt boyutları (Olumlu Dini Başa Çıkma ve Olumsuz Dini Başa Çıkma) ile cinsiyet arasında analiz yapılmış olması.

4-Araştırmada etki büyüklüğü hesaplanacağı için çalışmalarda istatistiki veriler (standart sapma, mean whitney $\mathrm{u}, \mathrm{n}, \mathrm{x}, \mathrm{sd}$, $\mathrm{t}$ değeri) tam ve eksiksiz bir şekilde verilmiş ayrıca çalışmaların hem kadın hem de erkeklere uygulanmış olması gerekmektedir.

\subsection{Meta-Analize Dâhil Edilecek Çalışmaların Belirlenmesi}

Araştırmada, çift aşamalı inceleme yapılmıştır. Birinci aşamada veri toplama işlemi için YÖK Ulusal Tez Merkezinde “Dini Başa Çıkma” konulu tezler aranmıştır. Tarama işlemine yıl (2019-2020), tezin yazıldığı Sosyal Bilimler Enstitüsü Felsefe ve Din Bilimleri Ana Bilim Dalı sınırı konularak arama yapılmıştır. İkinci aşamada bulunan tüm çalışmalar incelenmiş, çalışmada Olumlu ve Olumsuz Dini Başa Çıkma analizleri olmayan, nicel araştırma yöntemi kullanılmayan, örneklemi sadece kadın ya da erkek olan, yapılan analizlerde etki büyüklüğü hesaplanacağı için gerekli verileri (örneğin mean whitney $u$ testi için $u$ ya da $z$ değeri) olmayan, ölçek ya da standart sapma değeri bulunmayan çalışmalar meta-analize dâhil edilmemiştir. Verilerin anlamlı hale getirilmesi için CMA (versiyon 3) programı kullanılmıştır. Araştırmada Şen ve Yıldırım (2020) tarafından oluşturulan kontrol listesi temel alınmıştır. ${ }^{12}$ Dâhil edilecek çalışmaların belirlenmesine ait akış şeması aşağıda gösterilmiştir:

Şekil 1: Akış Şeması

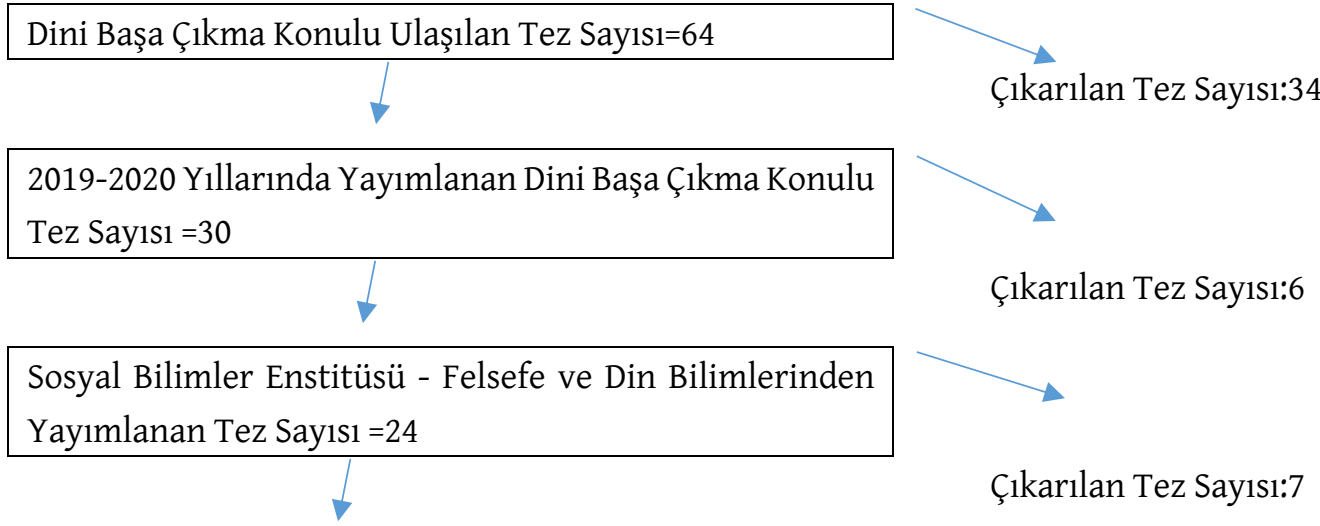

${ }^{12}$ Sedat Şen - İbrahim Yıldırım, CMA İle Meta-Analiz Uygulamaları (Ankara: Anı Yayıncılık, 2020), 111. 
Ercan - Kula, The Effect of Gender on Religious Coping: Meta-Analysis

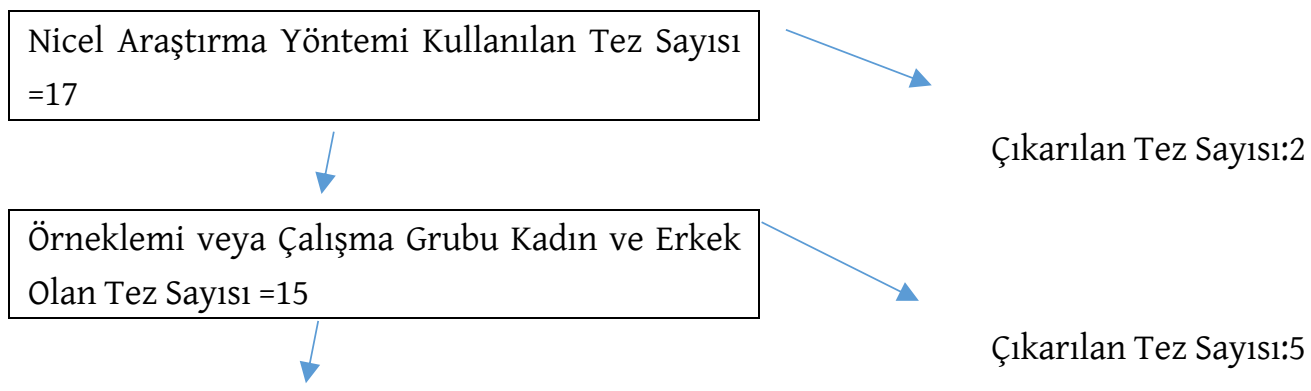

İstatistiki Verileri Tam ve Eksiksiz Olan Tez

Say1s $1=10$

Tablo 1: Meta-Analize Dâhil Edilen Çalışmalar

\begin{tabular}{lccc} 
& & $\underline{\mathbf{N}}$ & \\
Yazarı ve Yılı & Kadın & Erkek & Toplam \\
\hline Savcı Bahçekapılı, 2019 & 50 & 58 & 128 \\
Aydın, 2019 & 158 & 128 & 286 \\
Ferah, 2019 & 67 & 51 & 118 \\
Bayraktutar, 2019 & 221 & 287 & 508 \\
Bektaş, 2019 & 611 & 206 & 817 \\
Sağlam Demirkan, 2020 & 291 & 31 & 322 \\
Yılmaz, 2020 & 31 & 16 & 47 \\
Akkaya Türkol, 2020 & 190 & 188 & 378 \\
Çolak, 2020 & 208 & 192 & 400 \\
Koparan, 2019 & 122 & 78 & 200 \\
\hline Toplam & 1949 & 1235 & 3184 \\
\hline
\end{tabular}

Meta-analize dâhil edilen çalışmalar sonucunda kadın sayısının 1949, erkek sayısının 1235, toplam kişi sayısının ise 3184 olduğu tespit edilmiştir.

\subsection{Verilerin Analizi}

Meta-analizde çalışmaları nicel olarak birleştirmek için, çalışmalar arasında karşılaştırılabilir ölçümler elde etme fikri meta-analizin başlangıç noktasıdır. Karşılaştırılabilir ölçüler elde etmek için Effect Size (ES) olarak ifade edilen endeks tanımlanmaktadır. Etki büyüklükleri bize değişkenler arasındaki ilişkilerin gücünü veya büyüklüğünü göstermektedir. Etki büyüklükleri her çalışma için 
hesaplanır, örneklem büyüklüğüne göre ağırlıklandırılır ve ardından genel bir etki büyüklüğü tanımlamak için ortalamaları alınmaktadır. ${ }^{13}$ Etki büyüklüğü yapılan işlem etkisinin büyüklüğünü veya (daha genel olarak) iki değişken arasındaki ilişkinin gücünü yansıtan bir değerdir. Etki büyüklüğü iki değişken arasındaki herhangibir ilişkiyi açıklayabilir. ${ }^{14}$ Meta-analiz araştırmalarında iki farklı araştırma modeli kullanılmaktadır. Bu model seçimi, çalışmaların ortak bir etki büyüklüğünü paylaşıp paylaşmadığına yönelik beklenti ve analizin gerçekleştirilme hedefine dayanmaktadır. Eğer araştırmada analize dâhil edilen tüm çalışmaların işlevsel olarak aynı olduğuna inanılıyor ayrıca araştırmanın amacı belirlenen popülasyon için ortak etki büyüklügüunü hesaplamak ve diğer popülasyonlara genelleme yapmak değil ise ve iki koşul karşılanıyorsa sabit etki modelini kullanmak uygundur. Araştırmacı bağımsız olarak çalışan araştırmacılar tarafından gerçekleştirilen bir dizi çalışmadan veri topladığında, tüm çalışmaların işlevsel olarak eşdeğer olması olası değildir. Bu çalışmalardaki konular veya müdahaleler, sonuçları etkileyecek şekillerde farklılık gösterebilir. Bu durumlarda rastgele etkiler modeli, sabit etkiler modelinden daha kolay gerekçelendirilir. ${ }^{15}$ Meta-analiz sosyal bilimler için gerçekleştiriliyorsa "rassal (rastgele)" etki modelinin uygulanması tavsiye edilmektedir. ${ }^{16}$ Araştırmada rassal etkiler modeli kullanılmıştır. Meta-analizde kullanılan üç endeks -Cohen's d, Glass's delta ve Hedges'g- standart sapma birimleri

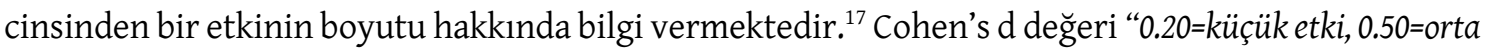
etki, $0.80=$ büyük etki” olarak tanımlanmaktadır. ${ }^{18}$ Cohen's d'den Hedges' g'ye dönüştürmek için bir düzeltme faktörü kullanılmaktadır. ${ }^{19}$ Çalışmaların Cohen's d değerlerini tespit etmek için çevrimiçi hesaplama araçları kullanılmıştır. ${ }^{20}$

\section{Bulgular}

\footnotetext{
${ }^{13}$ M.W. Lipsey - D.B. Wilson, Practical Meta-Analysis (Thousand Oaks, CA: Sage Publications, 2001)'den akt. Littell vd., Systematic Reviews and Meta-Analysis, 17.

${ }^{14}$ Michael Borenstein vd., Introduction to Meta-Analysis (West Sussex, UK: John Wiley \& Sons, 2009), 3-4.

${ }^{15}$ Borenstein vd., Introduction to Meta-Analysis, 83-84.

${ }^{16}$ A.P. Field - R. Gillett, "How to do a Meta-Analysis", British Journal of Mathematical and Statistical Psychology 63/3 (2010), 665-694; T.D. Pigott - J.R. Polanin, "Methodological Guidance Paper: High-Quality Meta-Analysis in a Systematic Review”, Review of Educational Research 90/1 (2020), 24-46'den akt. Şen - Yıldırım, CMA İle Meta-Analiz Uygulamaları, 6061.

${ }^{17}$ Paul D. Ellis, The Essential Guide to Effect Sizes Statistical Power, Meta-Analysis, and the Interpretation of Research Results (Cambridge: Cambridge University Press, 2010), 10.

${ }^{18}$ Jacob Cohen, Statistical Power Analysis for the Behavioral Sciences (USA: Lawrence Erlbaum Associates, 1988), 40.

${ }^{19}$ Borenstein vd., Introduction to Meta-Analysis, 27.

${ }^{20}$ D.B. Wilson, "Ph.D. (n.d.). Practical Meta-Analysis Effect Size Calculator [Online Calculator].June 02, 2021, Turkey", Campbell Collaboration (Erişim 02 Haziran 2021); W. Lenhart - A. Lenhart, "Calculation of Effect Sizes", https://www.psychometrica.de/effect_size.html. Dettelbach(Germany): Psychometrica:DOI: 10.13140/RG.2.2.17823.92329, (2016), (Erişim 02 Haziran 2021).
} 


\subsection{Etki Büyüklükleri ve Heterojenlik Testi ile Orman Grafikleri}

\subsubsection{Olumlu Dini Başa Çıkma}

Tablo 2: Etki Büyüklükleri ve Heterojenlik Testi (Olumlu Dini Başa Çıkma)

\begin{tabular}{lllllllllll} 
Model & $\mathbf{n}$ & O.E.B. & $\mathbf{Z}$ & S.H. & Alt Sinır & Üst Sinır & sd & $\mathbf{Q}$ & $\mathbf{p}$ & $\mathbf{I}^{\mathbf{2}}$ \\
\hline S.E.M. & 10 & 0,011 & 0,305 & 0,035 & $-0,058$ & 0,08 \\
R.E.M. & 10 & $-0,009$ & $-0,103$ & 0,091 & $-0,187$ & 0,168 & 9 & 52,73 & 0,918 & 82,934 \\
\hline
\end{tabular}

Not: O.E.B=Ortalama Etki Büyüklüğü; S.H.=Standart Hata; S.E.M.=Sabit Etkiler Modeli; R.E.M.=Rassal Etkiler Modeli

Heterojenliği saptamak için istatistiksel yöntemlerle ilgili sorunlar nedeniyle, çalışmalar arasındaki tutarsızlığın derecesini ölçerek heterojenliğin bir meta-analiz üzerindeki etkisini tanımlayan $\mathrm{I}^{2}$ adlı yeni bir nicelik geliştirilmiştir. ${ }^{21} \mathrm{I}^{2}$ değeri bizlere araştırmaların bulunan varyans değerlerinin şans yardımı ile değil de araştırmaların heterojenliğinden dolayı oluştuğunu ifade etmektedir. ${ }^{22}$ Higgins ve Thompson (2002), I I değerini " $I^{2}=\% 25$ küçük heterojenlik, $I^{2}=\% 50$ orta heterojenlik, I'=\%75 büyük heterojenlik" olarak yorumlamaktadır. ${ }^{23}$ Heterojenlik testi sonucunda $\% 95$ güven aralığında rastgele (rassal) etkiler modeline göre $Q$ değeri=52,73; p değeri=0,918; sd değeri=9; $I^{2}$ değeri=82,934 olarak tespit edilmiştir. $I^{2}$ değeri=82,934 olduğu için Higgins ve Thompson'a (2002) göre büyük heterojenlik sağlanmaktadır. ${ }^{24}$

\footnotetext{
${ }^{21}$ J. Higgins vd., “Measuring Inconsistency in Meta-Analyses”, British Medical Journal 3 (2003), 557-560'den akt. ; Mark Petticrew - Helen Roberts, Systematic Reviews in the Social Sciences: A Practical Guide (UK: Blackwell Publishing, 2006), 217.

${ }^{22}$ Şen - Yıldırım, CMA İle Meta-Analiz Uygulamaları, 76.

${ }^{23}$ Julian Higgins - Simon Thompson, "Quantifying Heterogeneity in a Meta-Analysis", Statistics in Medicine 21/11 (2002), 1539-1558'den akt. William R. Shadish - C. Keith Haddock, “Combining Estimates of Effect Size”, The Handbook of Research Synthesis and Meta-Analysis, ed. Harris Cooper vd. (New York: Russell Sage Foundation, 2009), 263.

${ }^{24}$ Higgins - Thompson, "Quantifying Heterogeneity in a Meta-Analysis"'den akt. Shadish - Haddock, "Combining Estimates of Effect Size”, 263.
} 
Ercan - Kula, Cinsiyetin Dini Başa Çıkma Üzerindeki Etkisi: Meta - Analiz

Şekil 2: Etki Büyüklüklerine İlişkin Forest Plot (Orman Grafiği) (Olumlu Dini Başa Çıkma)

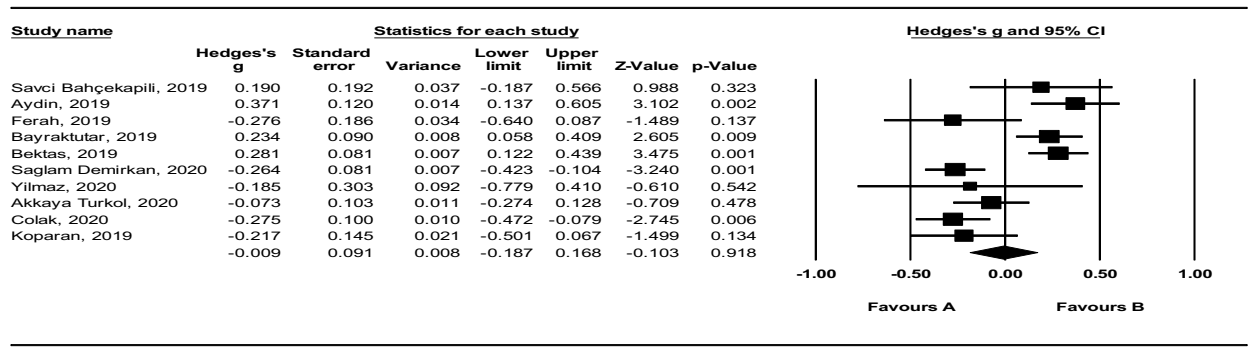

Meta Analysis

Cinsiyetin olumlu dini başa çıkma üzerindeki etkisini tespit etmek için yapılan meta-analiz sonucunda Hedges's g=-0,009 olduğu tespit edilmiştir. Hedges's g değerinin negatif olması olumlu dini başa çıkma düzeyinin erkekler lehine olduğuna işaret etmektedir. Ancak değerin sıfıra çok yakın olması ve değerin 0,2'den küçük olması etkinin düşük düzeyinde altında olduğunu göstermektedir. Bu bağlamda cinsiyetin olumlu dini başa çıkma üzerindeki etkisi ile ilgili olarak Hedges's g değerinin düşük düzeyin altında olmasından dolayı kadın ile erkek arasında farkın olmadığı görülmektedir.

\subsubsection{Olumsuz Dini Başa Çıma}

Tablo 2: Etki Büyüklükleri ve Heterojenlik Testi (Olumsuz Dini Başa Çıkma)

\begin{tabular}{lllllllllll} 
& \multicolumn{1}{c}{ \%95'lik } \\
Model & $\mathbf{n}$ & O.E.B. & $\mathbf{Z}$ & S.H. & Alt Sinır & Üst Sınır & sd & $\mathbf{Q}$ & $\mathbf{p}$ & $\mathbf{I}^{\mathbf{2}}$ \\
\hline S.E.M. & 10 & 0,085 & 2,42 & 0,035 & 0,016 & 0,154 & & & & \\
R.E.M. & 10 & 0,099 & 1,571 & 0,063 & $-0,024$ & 0,222 & 9 & 24,92 & 0,116 & 63,897 \\
\hline
\end{tabular}

Not: O.E.B=Ortalama Etki Büyüklüğü; S.H.=Standart Hata; S.E.M.=Sabit Etkiler Modeli; R.E.M.=Rassal Etkiler Modeli

Heterojenlik testi sonucunda \%95 güven aralığında rastgele (rassal) etkiler modeline göre Q değeri=24,92; p değeri=0,116; sd değeri=9; $I^{2}$ değeri=63,897 olarak tespit edilmiştir. $I^{2}$ değeri=63,897 olduğu için Higgins ve Thompson'a (2002) göre orta heterojenlik sağlanmaktadır. ${ }^{25}$

\footnotetext{
${ }^{25}$ Higgins - Thompson, "Quantifying Heterogeneity in a Meta-Analysis”'den akt. Shadish - Haddock, "Combining Estimates of Effect Size”, 263.
} 
Ercan - Kula, The Effect of Gender on Religious Coping: Meta-Analysis

Şekil 3: Etki Büyüklüklerine İlişkin Forest Plot (Orman Grafiği) (Olumsuz Dini Başa Çıkma)

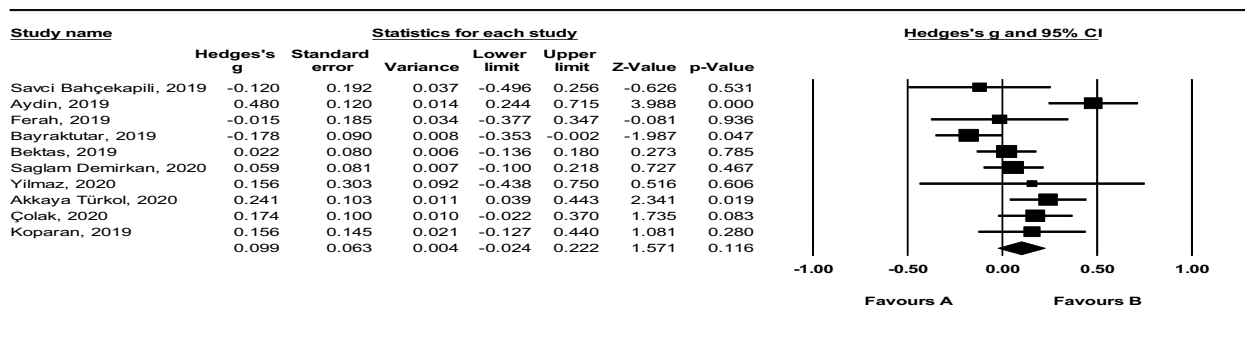

Meta Analysis

Cinsiyetin olumsuz dini başa çıkma üzerindeki etkisini tespit etmek için yapılan meta-analiz sonucunda Hedges's g=0,099 olduğu tespit edilmiştir. Hedges's g değerinin pozitif olması olumsuz dini başa çıkma düzeyinin kadınlar lehine olduğuna işaret etmektedir. Ancak değerin sıfırdan kısmen uzaklaşması ve değerin 0,2 'den küçük olması etkinin düşük düzeyinde altında olduğunu göstermektedir. Bu bağlamda cinsiyetin olumsuz dini başa çıma üzerindeki etkisi ile ilgili olarak Hedges's g değerinin düşük düzeyin altında olmasından dolayı kadın ile erkek arasında farkın olmadığı görülmektedir.

\subsection{Yayım Yanlılı̆̆1}

\subsubsection{Olumlu Dini Başa Çıkma}

Şekil 4: Olumlu Dini Başa Çıkma İçin Huni Grafiği

Funnel Plot of Standard Error by Hedges's g

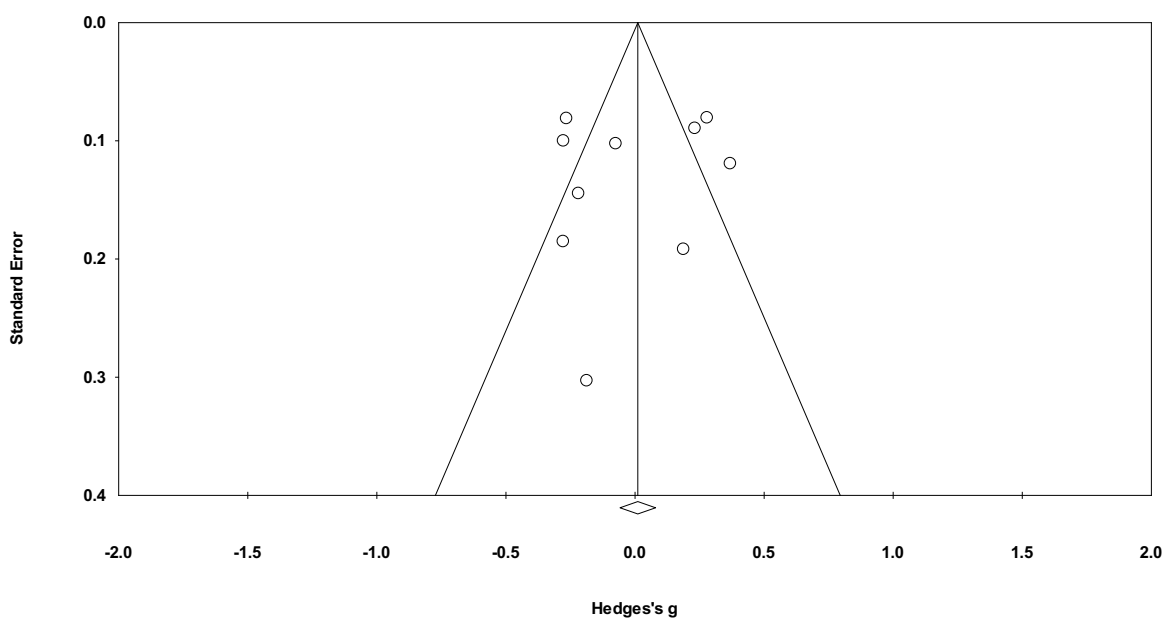


Light ve Pillemer (1984), Huni grafiğinin yayım yanlılığının olma ihtimalinin belirlenmesinde kullanılabileceğini ifade etmektedir. ${ }^{26}$ Yayım yanlılığının tespiti için Egger's testi ${ }^{27}$, Begg ve Mazumdar testi ${ }^{28}$, Duval ve Tweedie's testi ${ }^{29}$, Classic fail-safe $\mathrm{N}^{30}$ hesaplaması yapılmıştır.

Huni grafiğinde çalışmaların simetrik dağıldığı görülmektedir. Olumlu Dini Başa Çıkma metaanalizi için yapılan Egger's testi p-değeri (2-tailed) $=0,71$ olarak tespit edilmiştir. Tespit edilen $p$ değeri (2-tailed)>0,05 olduğu için yayım yanlılığ yoktur. Araştırmada Kendall tau b değeri (2tailed) $=0,92$ olarak tespit edilmiştir. Tespit edilen değer (2-tailed) $>0,05$ olduğu için yayım yanlılığ 1 yoktur. Classic fail-safe $\mathrm{N}$ hesaplaması 0 olarak tespit edilmiştir.

Tablo 4: Olumlu Dini Başa Çıkma İçin Duval ve Tweedie’s Testi

\%95’lik

\begin{tabular}{llllll} 
Değer & Çıkarılmış Çalışma & Nokta Tahmini & Alt limit & Üst Limit & Q \\
\hline G.D. & - & 0 & $-0,018$ & 0,16 & 52,7 \\
D.D. & 0 & 0 & $-0,018$ & 0,16 & 52,7 \\
\hline
\end{tabular}

Notlar: G.D.=Gözlenen Değer; D.D.= Düzeltilmiş Değer

Duval ve Tweedie's testi yapılan analizin yayım yanlılığını sonlandırmak için düzeltme eklenecek yayın sayısını ifade etmektedir. Yapılan teste göre \%95 güven aralığında araştırmaya yayım yanlılığını sonlandırmak için yayın eklenmesi gerekmemektedir.

\subsubsection{Olumsuz Dini Başa Çıma}

\footnotetext{
${ }^{26}$ R.J. Light - D.B. Pillemer, Summing Up: The Science of Reviewing Research (Cambridge, MA: Harvard University Press, 1984)'den akt. Şen - Yıldırım, CMA İle Meta-Analiz Uygulamaları, 98.

${ }^{27}$ Matthias Egger vd., "Bias in Meta-Analysis Detected by a Simple, Graphical Test”, BMJ 315/ (01 Eylül 1997), 629-634.

${ }^{28}$ Colin B. Begg - Madhuchhanda Mazumdar, "Operating Characteristics of a Rank Correlation Test for Publication Bias", Biometrics 50/4 (1994), 1088-1101.

${ }^{29}$ Sue Duval - Richard Tweedie, “A Nonparametric ‘Trim and Fill' Method of Accounting for Publication Bias in MetaAnalysis", Journal of The American Statistical Association 95/ (01 Mart 2000), 89-98.

${ }^{30}$ Borenstein vd., Introduction to Meta-Analysis, 284-285.
} 
Şekil 5: Olumsuz Dini Başa Çıkma İçin Huni Grafiği

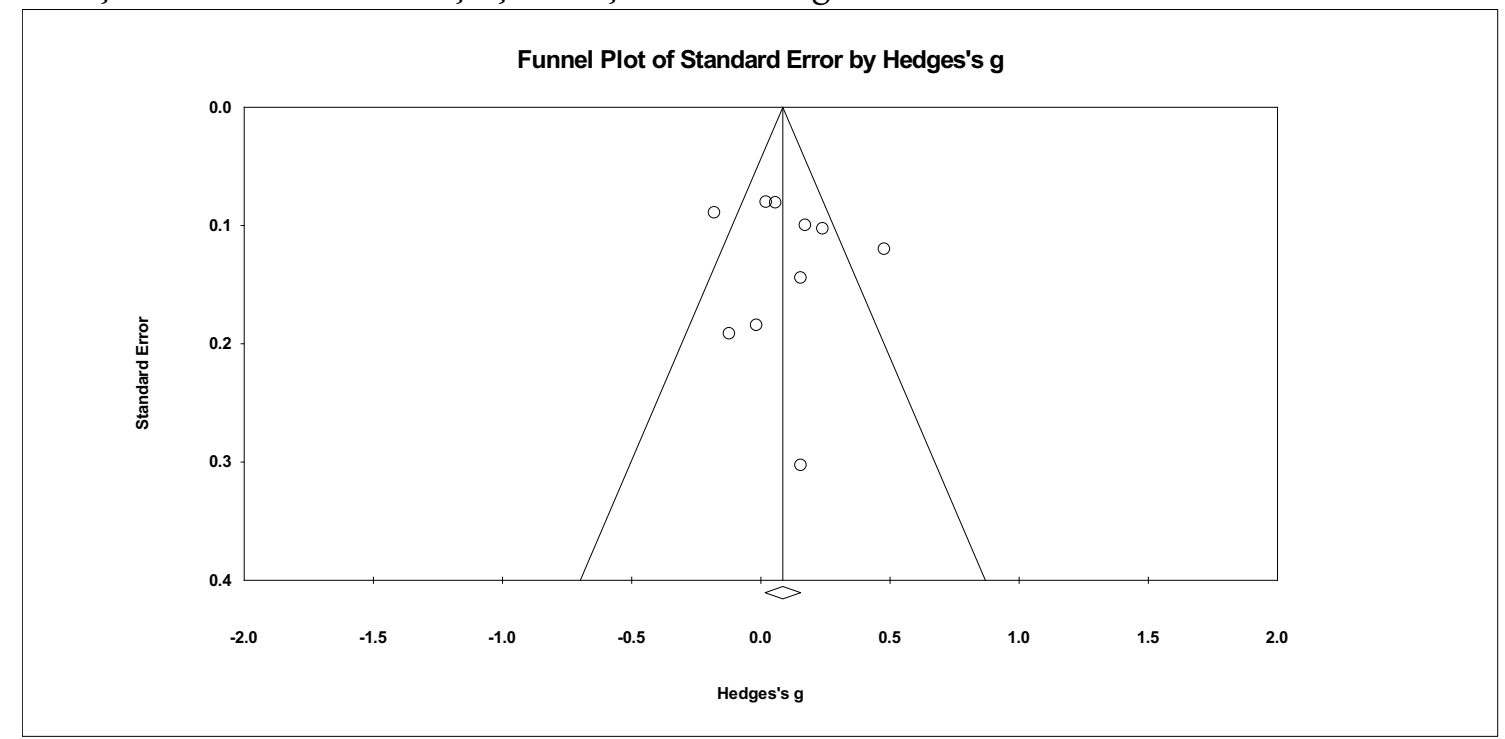

Huni grafiğinde çalışmaların simetrik dağıldığı görülmektedir. Olumsuz Dini Başa Çıkma metaanalizi için yapılan Egger's testi p-değeri (2-tailed) $=0,69$ olarak tespit edilmiştir. Tespit edilen $p$ değeri (2-tailed) $>0,05$ olduğu için yayım yanlılığ yoktur. Araştırmada Kendall tau b değeri (2tailed) $=0,78$ olarak tespit edilmiştir. Tespit edilen değer (2-tailed) $>0,05$ olduğu için yayım yanlıllı̆ 1 yoktur. Classic fail-safe $\mathrm{N}$ hesaplaması 7 olarak tespit edilmiştir.

Tablo 5: Olumsuz Dini Başa Çıkma İçin Duval ve Tweedie's Testi

\%95'lik

\begin{tabular}{llllll} 
Değer & Çıkarılmış Çalışma & Nokta Tahmini & Alt limit & Üst Limit & Q \\
\hline G.D & - & 0,098 & $-0,02$ & 0,22 & 24,92 \\
D.D. & 0 & 0,098 & $-0,02$ & 0,22 & 24,92 \\
\hline
\end{tabular}

Notlar: G.D.=Gözlenen Değer; D.D.= Düzeltilmiş Değer

Duval ve Tweedie's testi yapılan analizin yayım yanlılığını sonlandırmak için düzeltme eklenecek yayın sayısını ifade etmektedir. Yapılan teste göre \%95 güven aralığında araştırmaya yayım yanlılığını sonlandırmak için yayın eklenmesi gerekmemektedir.

\section{Değerlendirme}

Cinsiyetin olumlu ve olumsuz dini başa çıkma düzeyi üzerindeki etkisi ile ilgili 2019-2020 yıllarında dini başa çıkma konulu toplam 10 adet tez dâhil edilerek yapılan meta-analiz araştırması 1949 kadın, 1235 erkek olmak üzere 3184 kişiden elde edilen veriyi kapsamaktadır. Olumlu ve olumsuz başa çıkma ile ilgili yapılan meta-analiz için etki büyüklükleri ve heterojenlik testleri 
Ercan - Kula, Cinsiyetin Dini Başa Çıkma Üzerindeki Etkisi: Meta - Analiz

yapılmıştır. Test sonuçlarında rastgele etkiler modeli uygulanmıştır. Olumlu dini başa çıkma için yapılan heterojenlik testinde $Q$ değeri $=52,73$; $p$ değeri=0,918; sd değeri=9; $I^{2}$ değeri $=82,934$ olarak tespit edilmiş ve $\mathrm{I}^{2}$ değerinden dolayı heterojen olduğuna karar verilmiştir. Olumlu dini başa çıkma için Hedges's g=-0,009 olarak tespit edilmiştir. Hedges's g değerinin 0,2'den küçük olması kadın ile erkek arasında fark olmadığını göstermektedir. Olumlu dini başa çıkma yayım yanlılı̆̆ı için huni grafiği yapılmış, Egger's testi p-değeri (2-tailed) $=0,71$; Kendall tau b değeri (2-tailed) $=0,92$ olarak tespit edilmiştir. Değerler 0,05'den büyük olduğu için yayım yanlılığı söz konusu değildir. Classic fail-safe $\mathrm{N}$ hesaplaması 0 olarak tespit edilmiştir. Duval ve Tweedie testi sonucuna göre yayım yanlılı̆̆ını bitirmek için yayın eklemek zorunluğunun olmadığı görülmüştür. Olumsuz dini başa çıkma için yapılan heterojenlik testinde $Q$ değeri=24,92; $p$ değeri=0,116; sd değeri=9; $I^{2}$ değeri=63,897 olarak tespit edilmiş ve $I^{2}$ değerinden dolayı heterojen olduğuna karar verilmiştir. Olumsuz dini başa çıkma için Hedges's g=0,099 olarak tespit edilmiştir. Hedges's g değerinin 0,2'den küçük olması kadın ile erkek arasında fark olmadığını göstermektedir. Olumsuz dini başa çıkma yayım yanlılı̆̆ı için huni grafiği yapılmış, Egger's testi p-değeri (2-tailed) $=0,69$; Kendall tau b değeri (2-tailed) $=0,78$ olarak tespit edilmiştir. Değerler 0,05 'den büyük olduğu için yayım yanlılığı söz konusu değildir. Classic fail-safe N hesaplaması 7 olarak tespit edilmiştir. Duval ve Tweedie testi sonucuna göre yayım yanlılığını bitirmek için yayın eklemek zorunluğunun olmadığı görülmüştür. Cinsiyetin olumlu dini başa çıkma üzerindeki etkisi olumlu dini başa çıkma için erkekler lehine, olumsuz dini başa çıkma için kadınlar lehine tespit edilse de tespit edilen değerlerin düşük düzeyin de altında önemsenmeyecek bir değere sahip olmasından dolayı cinsiyetin dini başa çıkma düzeyi üzerinde etkisinin olmadığı tespit edilmiştir.

\section{Sonuç ve Öneriler}

Yapılan meta-analiz araştırmasında cinsiyetin dini başa çıkma düzeyine etki etmediği tespit edilmiştir. Araştırma alanda dini başa çıkma ile ilgili yapılan ilk meta-analiz çalışmasıdır. Gelecek çalışmalar için dâhil edilme kriterlerinin değiştirilmesinin ve araştırmada moderatör etkiler incelenmediğinden gelecek çalışmalara moderatör etkilerinde dâhil edilerek yapılmasının alana fayda sağlayacağı düşünülmektedir.

\section{Kaynakça}

*Akkaya Türkol, Yeliz. Kişilik Özellikleri ve Dini Başa Çıkma Arasındaki İlişkinin İncelenmesi (Çorum Örneği). Çorum: Hitit Üniversitesi Sosyal Bilimler Enstitüsü, Yüksek Lisans, 2020.

*Aydın, Ragıp. Çalışan Bireylerde Yaşam Doyumu, Mesleki Tükenmişlik ve Dini Başa Çıkma Arasındaki İlişkinin İncelenmesi. Kastamonu: Kastamonu Üniversitesi Sosyal Bilimler Enstitüsü, Yüksek Lisans, 2019. 
Ayten, Ali. Tanrı'ya Sı̆̆ınmak Dini Başa Çıkma Üzerine Psiko-Sosyal Bir Araştırma. İstanbul: İz Yayıncllık, 2012.

Ayten, Ali - Yıldız, Refik. "Ali Ayten, Refik Yıldız-Dindarlık, Hayat Memnuniyeti İlişkisinde Dinî Başa Çıkmanın Rolü Nedir Emekliler Üzerine Bir Araştırma”. Dinbilimleri Akademik Araştırma Dergisi 16/1 (2016).

*Bayraktutar, Merve. İmam Hatip Lisesi Öğrencileri Örnekleminde Dini Başa Çıkma ve Tanrı Tasavvuru İlişkisi. İstanbul: Marmara Üniversitesi Sosyal Bilimler Enstitüsü, Yüksek Lisans, 2019.

Begg, Colin B. - Mazumdar, Madhuchhanda. "Operating Characteristics of a Rank Correlation Test for Publication Bias”. Biometrics 50/4 (1994), 1088-1101.

*Bektaş, Sueda. Ergenlerde Benlik Saygısı ve Dini Başa Çıkma (İmam Hatip Öğrencileri Örneği). İstanbul: Marmara Üniversitesi Sosyal Bilimler Enstitüsü, Yüksek Lisans, 2019.

Borenstein, Michael vd. Introduction to Meta-Analysis. West Sussex, UK: John Wiley \& Sons, 2009.

Cohen, Jacob. Statistical Power Analysis for the Behavioral Sciences. USA: Lawrence Erlbaum Associates, 2.b., 1988.

*Çolak, Muharrem Bilal. İssizlik, Stres ve Dini Başa Çıkma. Çorum: Hitit Üniversitesi Sosyal Bilimler Enstitüsü, Yüksek Lisans, 2020.

Duval, Sue - Tweedie, Richard. "A Nonparametric 'Trim and Fill' Method of Accounting for Publication Bias in Meta-Analysis". Journal of The American Statistical Association 95/ (01 Mart 2000), 89-98. https://doi.org/10.1080/01621459.2000.10473905

Egger, Matthias vd. "Bias in Meta-Analysis Detected by a Simple, Graphical Test”. BMJ 315/ (01 Eylül 1997), 629-634.

Ekşi, Halil. Başaçıkma, Dini Başaçıkma ve Ruh Sağlığı Arasındaki İlişki Üzerine Bir Araştırma: Eğitim, İlahiyat ve Mühendislik Fakültesi Öğrencilerinin Karşılaştırılması. Bursa: Uludağ Üniversitesi Sosyal Bilimler Enstitüsü, Doktora, 2001.

Ellis, Paul D. The Essential Guide to Effect Sizes Statistical Power, Meta-Analysis, and the Interpretation of Research Results. Cambridge: Cambridge University Press, 2010.

*Ferah, Nimet. Boşanma Sürecindeki Bireylerde Dini Başa Çıkma Davranışlarının Analizi. Sakarya: Sakarya Üniversitesi Sosyal Bilimler Enstitüsü, Doktora, 2019. 
Hunter, John E. - Schmidt, Frank L. Methods of Meta-Analysis: Correcting Error and Bias in Research Findings. USA: Sage Publications, 3. b., 2015.

Klaassen, Derrick W. vd. "Advance in the Study of Religious and Spiritual Coping". Handbook of Multicultural Perspectives on Stress and Coping. ed. Paul T. P. Wong - Lilian C. J. Wong. 105-132. USA: Springer, 2006.

*Koparan, Yasemin. Suriyeli Öğrencilerde Sinav Kaygısı ve Dini Başa Çıłkma İlişkisi Üzerine Bir Araştırma. Bursa: Bursa Uludağ Üniversitesi Sosyal Bilimler Enstitüsü, Yüksek Lisans, 2019.

Lenhart, W. - Lenhart, A. "Calculation of Effect Sizes". "Retrieved from": https://www.psychometrica.de/effect_size.html. Dettelbach (Germany): Psychometrica: DOI: 10.13140/RG.2.2.17823.92329, Erişim 02 Haziran 2021.

Littell, Julia H. vd. Systematic Reviews and Meta-Analysis. New York: Oxford University Press, 2008.

Murat, Ayşe - Kızılgeçit, Muhammed. “Dini Başa Çıkma ve Psikopatoloji İlişkisi (Rize Örneği)”. Recep Tayyip Erdoğan Üniversitesi İlahiyat Fakültesi Dergisi 6/11 (30 Haziran 2017), 111-151.

Özcan, Zeynep. "Mülteci Öğrencilerin Kültürel Uyumları ile Dinî Başa Çıkmaları Arasındaki İlişki Üzerine Bir Araştırma". Cumhuriyet İlahiyat Dergisi 23/1 (15 Haziran 2019), 127-147. https://doi.org/10.18505/cuid.510680

Pargament, Kenneth I. vd. "Başa Çıkanın Dinî Boyutu: Teori, Araştırma ve Uygulamadaki Gelişmeler”. çev. Çiğdem Damla Balaban. Din ve Maneviyat Psikolojisi Yeni Yaklaşımlar ve Uygulama Alanları. Çev. ed. İhsan Çapcıoğlu - Ali Ayten. der. Raymond F. Paloutzian - Crystal L. Park. 377-407. Ankara: Phoenix, 2013.

Pargament, Kenneth I. vd. "Patterns of Positive and Negative Religious Coping with Major Life Stressors". Journal for the Scientific Study of Religion 37/4 (01 1998), 710-724. https://doi.org/10.2307/1388152

Pargament, Kenneth I. - Park, Crystal L. "Merely a Defense? The Variety of Religious Means and Ends". Journal of Sociaf Issues 51/2 (1995), 13-32.

Pargament, Kenneth I. - Raiya, Hisham Abu. "A Decade Of Research on the Psychology of Religion and Coping: Things we Assumed and Lessons we Learned". Psyke \& Logos 28 (2007), 742-766.

Petticrew, Mark - Roberts, Helen. Systematic Reviews in the Social Sciences: A Practical Guide. UK: Blackwell Publishing, 2006. 
*Sağlam Demirkan, Fatma. Diyaliz Hastalarında Bağlanma, Dini Başa Çıkma ve Yaşam Memnuniyeti Arasındaki İlişki Üzerine Bir Araștırma. İstanbul: İstanbul Üniversitesi Sosyal Bilimler Enstitüsü, Doktora, 2020.

*Savcı Bahçekapıll, Sevgi. Görme Yetersizliği Olan Bireyler ve Dini Başa Çıkma. İzmir: İzmir Kâtip Çelebi Üniversitesi Sosyal Bilimler Enstitüsü, Yüksek Lisans, 2019.

Shadish, William R. - Haddock, C. Keith. "Combining Estimates of Effect Size". The Handbook of Research Synthesis and Meta-Analysis. ed. Harris Cooper vd. 257-277. New York: Russell Sage Foundation, 2. b., 2009.

Şen, Sedat - Yıldırım, İbrahim. CMA İle Meta-Analiz Uygulamaları. Ankara: Anı Yayıncılık, 2020.

Şentepe, Ayşe. "Yaşlılık Döneminde Dini Başaçıkma”. İnsan ve Toplum Bilimleri Araştırmaları Dergisi 4/1 (2015), 186-204.

Wilson, D.B. "Ph.D. (n.d.). Practical Meta-Analysis Effect Size Calculator [Online Calculator].June 02, 2021, Turkey”. Campbell Collaboration. Erişim 02 Haziran 2021. https://www.campbellcollaboration.org/research-resources/effect-size-calculator.html

*Yılmaz, Beyzanur. Dini Başa Çıkma Düzeyinin Takıntılı Davranışlarla Başa Çıkma İle İlişkisi Üzerine Bir Araştırma. Ankara: Ankara Üniversitesi Sosyal Bilimler Enstitüsü, Yüksek Lisans, 2020.

* (Yıldız) ile işaretlenen çalışmalar, meta - analize dâhil edilmiştir. 


\title{
The Effect of Gender on Religious Coping: Meta - Analysis
}

\author{
Soner ERCAN - Doç. Dr. M. Naci KULA
}

\section{Extended Summary}

The effect of gender on religious coping, which is one of the main subjects of the psychology of religion, is investigated by meta-analysis method. The fact that it is the first meta-analysis on religious coping in the field indicates the importance of the research. In addition, since metaanalysis research is the research of the researches on the subject, it is aimed to ensure that the relationship between gender and religious coping is understood in the light of the data of the researches. Inclusion criteria were determined to determine which studies would be included in the meta-analysis. The studies to be included in the meta-analysis were carried out in the philosophy and religious sciences departments of the social sciences institutes of the universities in 2019-2020, from the master's or doctoral theses registered on the website of the YÖK National Thesis Center, the sample of which included two groups as male and female, in the study positive and negative They are the ones whose analyzes are made for coping and whose statistical data are complete. In the first stage, 64 studies were reached, studies that met the inclusion criteria from 64 studies were examined in line with the flow chart, and 10 studies were included in the meta-analysis. As a result of 10 studies, it was determined that the number of people in the female sample, which was metaanalyzed, was 1949, the number of people in the male sample was 1235 , and the total number of people was 3184. CMA (version 3) program was used to make the data meaningful. Meta-analysis studies are divided into two models, fixed and random effects models. Random effects model was used in the research. In meta-analysis studies, effect sizes are expressed by Cohen's d, Glass's delta and Hedges'g indexes. Online calculation instruments were used to determine the Cohen's d values of the studies. Along with the determination of Cohen's $d$ values of the studies, the calculation of the effect sizes was carried out over Hedges's g values. In the study, effect sizes and heterogeneity tests, forest and funnel plots were made for both positive religious coping and negative religious coping. Heterogeneity test for positive religious coping according to random effects model, $Q$ value $=52.73$ at $95 \%$ confidence interval; $p$-value $=0.918$; $\mathrm{sd}$ value $=9$; The value of $\mathrm{I}^{2}$ was determined as 82,934 and it was seen that the heterogeneity of the distribution was provided. According to the forest chart for positive religious coping, Hedges's $g$ value was found to be -0.009 . A negative value for Hedges's g value indicates that positive religious coping level is in favor of men in interpreting the effect of gender on religious coping. However, the detection of Hedges's g value as -0.009 also shows that there is no difference between men and women for positive religious coping. According to the random effects model of the heterogeneity test for negative religious coping, $Q$ value $=24.92$ at the $95 \%$ confidence interval; $\mathrm{p}$-value $=0.116$; sd value $=9$; The value of $\mathrm{I}^{2}$ was determined as 63,897 
and it was seen that the heterogeneity of the distribution was provided. According to the forest graph for negative religious coping, Hedges's $g$ value was determined as $=0.099$. A positive value for Hedges' $g$ value indicates that negative religious coping level is in favor of women in interpreting the effect of gender on religious coping. However, the Hedges's $g$ value of 0.099 indicates that there is no difference between men and women for negative religious coping. Egger's test for positive religious coping revealed a $p$-value (2-tailed) $=0.71$ and since the determined $p$-value (2-tailed) $>0.05$, it was seen that there was no publication bias compared to Egger's test. In addition, Kendall tau $b$ value for positive religious coping was determined as (2-tailed) $=0.92$ and there was no publication bias since the determined Kendall tau b value (2-tailed) $>0.05$. According to Duval and Tweedie's test, which was conducted to eliminate publication bias, it is seen that it is not necessary to add publications to the research at the $95 \%$ confidence interval. The Classic fail-safe $\mathrm{N}$ calculation for positive religious coping was detected as 0 . In the funnel plot used to determine the publication bias for negative religious coping, it is seen that the studies are distributed symmetrically. Egger's test for negative religious coping revealed a $p$-value (2-tailed) $=0.69$ and since the determined $p$-value (2tailed) $>0.05$, there was no publication bias compared to Egger's test. In addition, Kendall tau $b$ value for negative religious coping was determined as (2-tailed) $=0.78$ and there was no publication bias since the determined Kendall tau $b$ value (2-tailed) $>0.05$. According to Duval and Tweedie's test, which was conducted to eliminate publication bias, it is seen that it is not necessary to add publications to the research at the $95 \%$ confidence interval. The Classic fail-safe $\mathrm{N}$ calculation for negative religious coping was detected as 0 . With the meta-analysis, it was determined that positive religious coping levels were in favor of men, and negative religious coping levels were in favor of women. However, it was determined that gender did not affect positive and negative religious coping levels, due to the effect sizes were less than 0.2 , which had an insignificant value. Since the research is the first meta-analysis on religious coping, it is thought that it would be beneficial to change the inclusion criteria for future studies.

Keywords: Study of Religion and Philosophy, Psychology of Religion, Gender, Religious Coping, Meta-Analysis 
Etki Büyüklüklerine İlişkin Forest Plot (Orman Grafiği) (Olumlu Dini Başa Çıma)

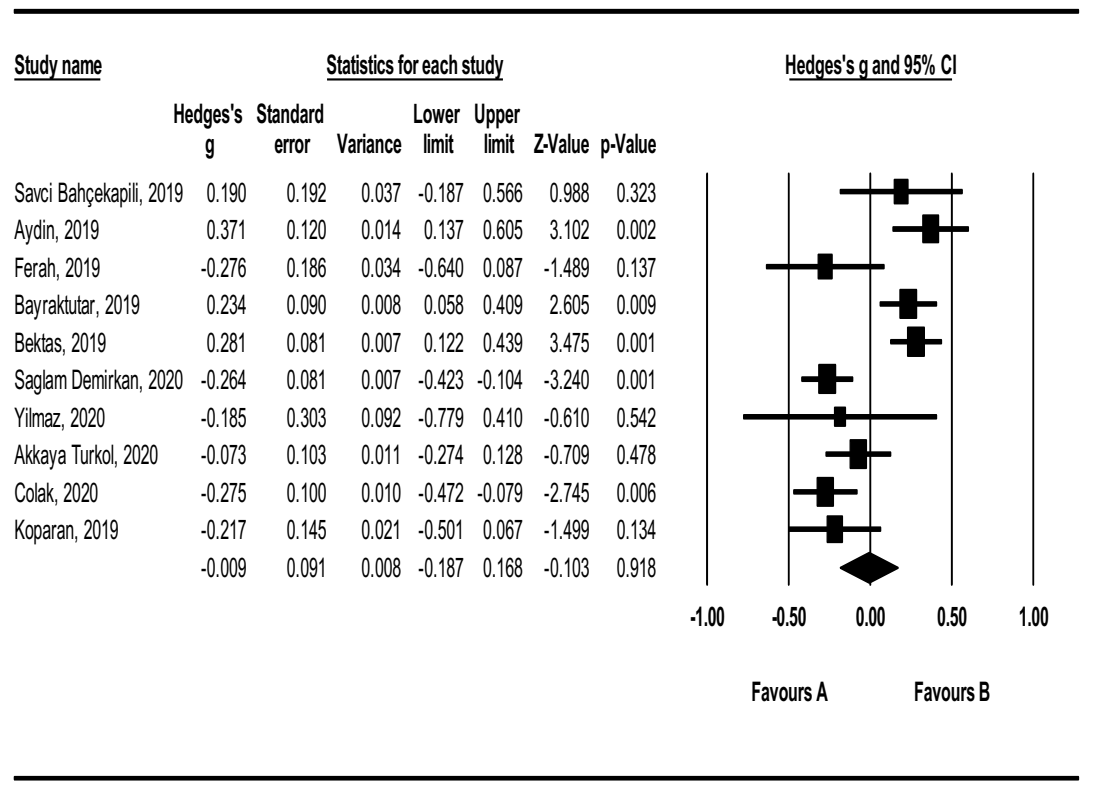

Meta Analysis

Etki Büyüklüklerine İlişkin Forest Plot (Orman Grafiği) (Olumsuz Dini Başa Çıkma)

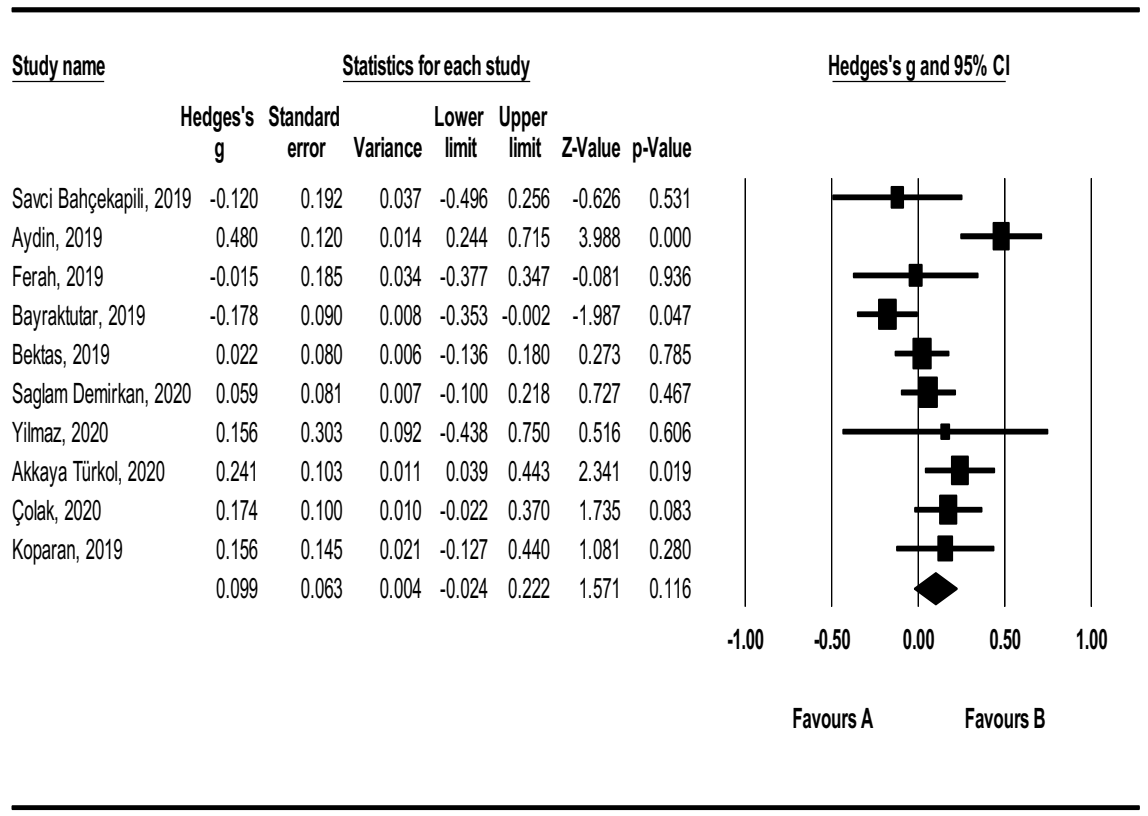

Meta Analysis 